\title{
Parental Food Beliefs on Pre-School-Aged Children in Kaski District of Nepal: A Qualitative Review
}

\author{
Jib Acharya ${ }^{1 *}$ 으, E.V. Teijlingen ${ }^{2}$, J. Murphy $^{3}$ and B. Ellahi ${ }^{4}$ \\ ${ }^{1}$ AANC Premium Services Ltd., Ickenham, Bournemouth University, Dorset-BH12 5BB, United Kingdom \\ ${ }^{2,3}$ Department of Health and Social Sciences, Bournemouth University, Dorset-BH12 5BB, United Kingdom \\ ${ }^{4}$ Department of Health and Social Care, University of Chester, Chester-CH1 4BJ, United Kingdom \\ ²evteilingen@bournemouth.ac.uk \\ 3jmurphy@bournemouth.ac.uk \\ ${ }^{4}$ b.ellahi@chester.ac.uk \\ 1*jib_acharya@mail.co.uk (Corresponding Author)
}

\section{ARTICLE INFORMATION}

Received: December 20, 2019

Revised: June 25, 2020

Accepted: June 30, 2020

Published Online: October 14, 2020

Keywords:

Malnutrition, Knowledge, Taboos,

Culture, Poverty, South Asia

\section{ABSTRACT}

Background: This study explores food beliefs among poor mothers related to feeding their offspring. Mothers' misconception of a healthy diet is one of the major causes of nutritional problems in preschool-aged children in Nepal and these beliefs and attitudes can result in the inappropriate feeding of young children.

Objectives: The main objectives of this study were:

- identify major barriers for recommending healthy food that are associated with existing cultures, religions and ethnic divisions;

- assess the knowledge, attitudes, and beliefs about nutritious food amongst mothers;

- assess health-seeking behaviour for children of low socio-economic status.

Methods: Study used a qualitative focus group discussion. Fifty participants took part in seven focus groups to explore their food beliefs. The qualitative focus groups aimed to collect in-depth information around food beliefs and data were thematically analysed.

Results: The study identified six key themes: (a) poverty; (b) knowledge; (c) policy; (d) beliefs about breastfeeding; (e) food beliefs: and (f) health-seeking behaviours/cultural influences. Many participants thought that illiterate and underserved populations are generally exposed due to financial scarcity, poor knowledge and strongly rooted in cultural practices, and beliefs. This study found 'diversified views' as a major barrier to food and health-seeking behaviours. Some groups recognised the negative effects of existing beliefs and taboos. However, the spiritual healers highlighted the importance of linking beliefs with cultural and religious norms and values. They showed the complex relationships between food and health-seeking behaviours and food recommendations with financial status and the perceived cultural practices of society.

Conclusions: This study suggests that a public health approach is needed to address nutrition problems associated with behaviour and revealed major barriers which were associated with poverty, resources, and mothers' education level.

\section{Introduction}

\section{Background}

In some societies within Asia and sub-Saharan Africa, women, old and sick people including young children are prohibited from eating certain foods due to taboos and cultural beliefs, and this may include nutritional foods
(Adhikari, 2010; Acharya, 2013; Acharya et al., 2015; 2016; 2017). Food beliefs are a systematised set of rules about which combinations of foods or foods one may or may not consume (Adhikari, 2010; Acharya, 2013; Acharya et al., 2016). However, food beliefs commonly target children under-five, pregnant women and sick people to prevent what is perceived as the negative effects of these 
foods on the target group (Adhikari, 2010; Acharya, 2013; Acharya, et al., 2015). For example, lactating and pregnant women and children under-five are usually prohibited from eating the nutritious foods a phenomena which commonly occurs in South Asian and African regions such as Bangladesh, India, Pakistan, Nigeria, Kennya, Ethiopia Congo among others (Odent, 2011). This is mainly because of the fear that the target groups may face difficulties in their entire life such as getting the common cold, diarrhoea, vomiting, constipation, delayed labour due to big babies among other fears. Such food taboos have also been strongly embedded within the communities in low and middle-income nations in Asia (Adhikari, 2010; Bista, Karki \& Thapa, 2010; Biza-Zepro, 2015). These strong taboos may limit the quality and quantity of food lactating and pregnant women may choose to consume or provide for their children (Bista, Karki \& Thapa, 2010; Acharya, 2013; Acharya et al., 2015; Biza-Zepro, 2015). For example, protein-rich foods such as meat, fish, eggs and legumes are often denied to pregnant women in many other populations and various parts of Asia and Africa (Adhikari, 2010; Bista, Karki \& Thapa, 2010; Acharya, 2013; Acharya et al., 2016).

However, studies on this topic are mostly from an anthropology or ethnographicperspective and don't examined the nutritional limitations of such practices. While different communities have cultural and traditional beliefs about "dangerous foods" for under-five children and women during lactation and pregnancy. To improve child development and promote maternal and child health, in some Asian and African communities, children, pregnant and lactating women are encouraged to diversify the foods consumed through the use of wild foods such as Dioscorea, wild yam and stinging nettles (Barun \& Clarke, 2006; Adhikari, 2010; Bista, Karki \& Thapa, 2010; Acharya, 2013; Acharya, et al., 2016).

Across the different geographical regions of Nepal, there is a diversity of food habits inspired byfood availability as well as cultural and traditional food beliefs which affect health and nutrition in both positive and negative ways (Adhikari, 2010; Acharya et al., 2016). Several misconceptions in relation to beliefs are regarding food and health-seeking behaviours which still exist in Nepal (Bista, Karki \& Thapa, 2010; Acharya, 2013). Sufficient nutritious food is important for the health of pregnant and lactating women and children whereas insufficient food consumption may lead to malnourishment.

Many studies in Nepal have focused on the link between nutrition and maternal and child health (Christian et al., 2006; Acharya, 2013; Acharya et al., 2016; Acharya et al., 2017). Some explored the widespread belief that pregnancy is a natural condition that does not need any particular attention (Subedi, 2008; Odent, 2011). Christian et al. report on rural women's eating habits during pregnancy in the Teraiwhere pregnant women reported avoiding eating green leafy vegetables, fruitsand dairy products as well as reducingportion sizes (Christian et al., 2006). This study further cited the commonly held belief that if a woman eats more during pregnancy, she will have a heavier baby which can cause problems during the delivery (Devkota et al., 2012; Acharya, 2013; Acharya et al., 2016). Acharya and colleagues (2015) revealed that the beliefs about food, healthy diet were strongly linked with cultural and religious norms.

There are many examples of superstitious beliefs and behaviours involving odd philosophies of causal relationships in South Asian and African regions (Fieldhouse, 1995). For these food and health beliefs, essential qualities of objects are viewed as magical and mystical and regarded as transferable from one object to another, for example through simple resemblance or through provisional contact (Acharya, 2013). A variety of such beliefs still persist in today's society (Hunter \& Shaw, 1989; Lindeman, Keskivaara \& Roschier, 2000; Toyama, 2000).

Food habits and practices are strictly linked to the wider culture (Ellahi, 2014). People follow codes of conduct in relation to food selection, consumption and preparation and eating habits (Adhikari, 2010). Nepal's traditional communities are based on social hierarchy and patriarchy (Acharya et al., 2015). The social hierarchy and patriarchy systems are the major generator of diversified views (multiple opinions) particularly for food recommendations in children, pregnant and lactating women (Christian et al., 2006).

Therefore, there is anurgent need to explore the social hierarchy and patriarchy in relation to food (Odent, 2011). We therefore aim to understand this by addressing the following questions: What are the maternal views about healthy food? What are the mothers' food and health-seeking behaviours towards preschool-aged children? What are the major factors that affect food recommendations? What are the influences that affect mothers feeding behaviours for preschool children and practice?

\section{Methods and Materials}

This research is a qualitative study (van Teijlingen \& Hundley, 2005) using Focus Groups Discussion (FGDs). FGDs were mostly conducted inlocal government offices or hotels. Three groups, out of seven, were literate and all discussions were held in Nepali. We conducted one pilot study consisting of nine people in Kaski district (van Teijlingen \& Hundley, 2005). The Nepal Health Research Council (NHRC) approved this study (reference no. 1438). 
Furthermore, written and verbal consent was obtained from the participants (Barun \& Clarke, 2006). None of the activities or procedures carried out in this study caused distress or discomfort to participants and key informants or any other members of their households (van Teijlingen $\&$ Hundley, 2005). Respondents were informed about the freedom to withdraw, non-discrimination and willingness to participate in the survey and FGD (Barun \& Clarke, 2006). The study also withdrew the participants who did not complete or wished to withdraw their participation from the study after data collection (Barun \& Clarke, 2006).

Seven different focus group discussions (see Table 1) were conducted with: (1) policy people; (2) auxiliary nurse midwives (ANMs); (3) health workers; (4) pharmacists; (5) social workers (Red Cross Volunteers); (6) spiritual healers; and (7) members of a mothers' group. Two groups out of seven (ANMs \& mothers') were involved inmaternal and infant health management, i.e. they provided care, support and conducted programme evaluations. There were between four and eleven participants in the seven focus groups. The discussion lasted 90 to120 minutes and all the data were recorded manually by researcher assistants, as consent to participate was obtained but a refusal to be audio recorded (Barun \& Clarke, 2006).

\subsection{Data Analysis}

These data were transcribed, translated into English and analysedusing the matic analysis (Barun \& Clarke, 2006; Bowling, 2014) applying the elements of the conceptual framework of Marks et al., (2001). By reading the transcripts possible themes were identified and then sections of data were structured into themes and sub-themes (Barun \& Clarke, 2006). The transcripts were analysed by the first author and verified by co-authors. Quotes illustrating key themes were then selected. The emerging themes were rearranged and refined and merged into six overarching themes (Barun \& Clarke, 2006; Bowling, 2014).

\section{Results}

\subsection{Demographics of the FGD (Focus Group Discussion) participants}

Fifty participants (33 men and 17 women) were recruited forming seven focus groups (Bowling, 2014). Table 1 presents the details of the demographic characteristics of the participants. Most FGD participants were men, Hindu and aged between 36 to 45 years.

The pharmacists' group was the smallest whereas the health workers' group was the largest. The auxiliary nurse midwives, health workers, and policy people worked for the local government. The mothers' group was also a part of the local government. Social workers were volunteers with the Nepal Red Cross Society. Pharmacists and spiritual healers were self-employed.

\subsection{Diversified views}

Figure 1 presents a summary of the views presented. It identifies a major barrier to recommend healthy diets for the preschool-aged children. This study explored the viewsof the diverse participants. Diversified views (DV) which refers to having multiple opinions at the same time appeared to exist in each household of the study population. The highlighted 'Influencing Factors' (the Figure 1) were strongly associated directly with the study's objectives. Non-highlighted factors are also important, but to a less direct degree than the influencing factors. Thus, the highlighted factors are often key/activating issues (Knowledge, Attitudes, Beliefs

Table 1: Demographics of FGD participants

\begin{tabular}{|l|c|c|c|c|c|c|c|c|}
\hline \multirow{2}{*}{\multicolumn{1}{c|}{ Role }} & \multicolumn{2}{|c|}{ Gender } & \multicolumn{4}{c|}{ Age Group Ratio } & \multicolumn{2}{c|}{ Religion } \\
\cline { 2 - 10 } & Male & Female & $25-35$ & $36-45$ & $46-55$ & $56-65$ & Hindu & $\begin{array}{c}\text { Buddhist / } \\
\text { Christian }\end{array}$ \\
\hline Pharmacists & 4 & - & 1 & 3 & - & - & 4 & - \\
\hline Auxiliary Nurse Midwives & - & 7 & 4 & 2 & 1 & - & 5 & 2 \\
\hline Spiritual Healers & 5 & - & - & - & - & 5 & 5 & - \\
\hline Mothers' Group & - & 7 & 2 & 3 & 1 & 1 & 3 & 4 \\
\hline Health Workers & 10 & 1 & 3 & 5 & 3 & - & 10 & 1 \\
\hline Social Workers & 9 & - & 3 & 2 & 3 & 1 & 9 & - \\
\hline Policy people & 5 & 2 & 3 & 3 & 1 & - & 7 & - \\
\hline Total (n=50) & 33 & 17 & 16 & 18 & 9 & 7 & 43 & 7 \\
\hline
\end{tabular}




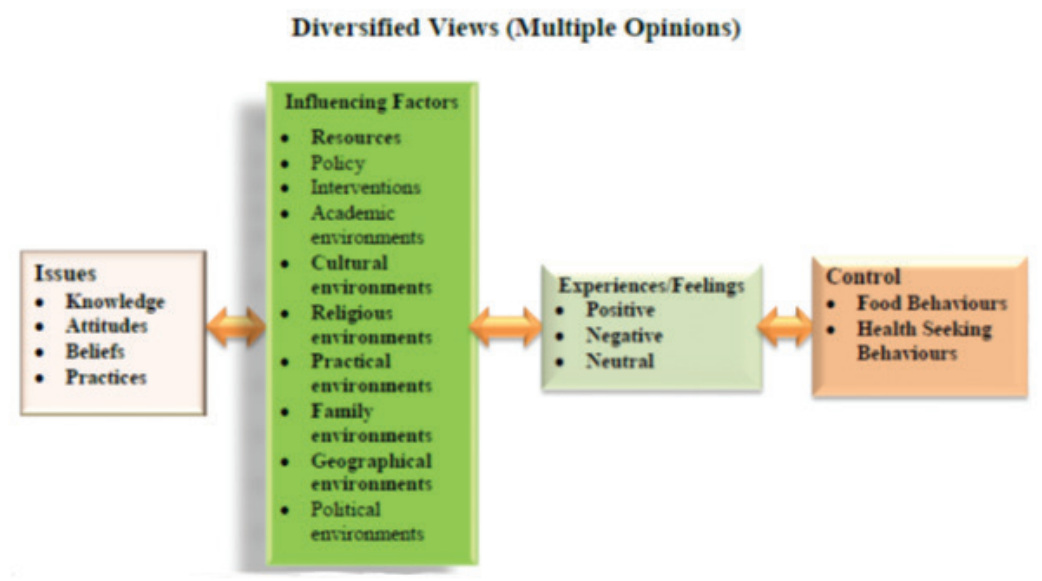

Figure 1: Diversified views: a major barrier to food recommendation.

and Practices) about healthy foods that reveal the positive, negative and neutral views which directly or indirectly influence food choice and health-seeking behaviour. The study found negative views towards healthy diet. DV emerged when the relatives, friends or neighbours visit a sick child's home. During the visit, these visitors generally collect information about the causes of child sickness, food given to child, and health services that the parents take the child to. Based on the visitors own past experienced, they give advice, sharing negative, positive and neutral views about both healthy diets and consultations with health workers. For example, if the child is suffering from common cold and fever, visitors often suggest that green leafy vegetables, fruits and yogurt should be avoided. These food suggestions are often based on Ayurvedic treatment systems which are associated with the several food restrictions based on the nature of the ailments. Similarly, they also recommend certain health institutions and professionals or traditional/ spiritual healers. With a number of visitors, the sick child's parents collect multiple opinions about the child sickness including food and health-seeking behaviours from visitors every day. Typically, these DV confuse the parents, which leads to delays in seeking medical and improvements in the child's diet. This study suggests that DV is a major hindrance in ensuring appropriate food and health-seeking behaviours are undertaken by parents.

The thematic analysis resulted in six key themes: (a) poverty; (b) knowledge; (c) policy; (d) beliefs about breastfeeding; (e) food beliefs; and (f) health-seeking behaviours/cultural influences.

\subsection{Poverty}

Members of all FGDs thought that poor, illiterate and underserved populations were vulnerable due to poor education and knowledge about healthy food and strongly associated with the existing cultural beliefs. Fruit, green vegetables, and another healthy commodity were seen as expensive. In the words of one mother:

"I cannot buy healthy foods due to lack of money as well as high prices."

(FGD: Mothers' Group).

Whilst the policy-people added:

"There is no choice for healthy diets by low-income groups because they are unable to afford dairy product o meat items, thus children from these groups are more susceptible to undernutrition."

(FGD: Policy People).

In Nepal, women's social status is generally low and even more so amongst the poorest. Poor women often work harder than men since they often work on the land and in the house. In some ethnic groups, women hardly have any time for child care and feeding. One of the health workers said:

"I have no time to care for my daughter due to loads of house and office work. My daughter is being cared for by my mother-in-law whose mind is completely occupied by beliefs and taboos mainly on child care and feeding."

(FGD: ANM).

Whilst one policy-maker noted that it is more than just a lack of money:

"Poor people of this area are deprived of basic capabilities rather than simply low income. They are also destitute of basic needs, rights and opportunities and suffering after the natural disaster."

(FGD: Policy People). 


\subsection{Knowledge}

This theme covers the level of mothers' knowledge about under nutrition as well as common healthy and nonhealthy foods and their availability. This theme centres on the question: "Why do beliefs and taboos frequently come into practice in very systematic behaviours and yet are also highly diversified into different platforms such as ethnic groups, castes, and religions?"Again, conflicting views were reported. For example, in one group colostrum feeding was encouraged and, in another it was rejected. Poor households did not focus on the condition of children, whereas rich households tried to attend to childhood problems urgently. This variation is due to different levels of knowledge. This theme is, of course, affected by the economic status of people.

In terms of knowledge about nutritious food, the FGDs revealed three different sub-themes. First, all groups suggested that the level of awareness about undernutrition was lacking in poor people, impacting on nutritional status such as non-exclusive breast feeding, inappropriate childfeeding practices, inadequate diet and rest for women during the pregnancy and insufficient health-seeking behaviours.

Secondly, most participants also regarded the low level of knowledge as one of the major factors for undernutrition, for example, one of the ANMs said that:

"I noticed one family who stayed next door to a subhealth post (SHP) in my working area, who had four children. The grandparents always used to recommend them ready-made foods. After one year these childrenthree out of four - were diagnosed with undernutrition by the SHP and sadly one died. After this episode, they realized that it was due to the regular feeding of readymade food. The people of this area have fairly poor knowledge of a healthy diet. It may be due to poverty and low level of education."

(FGD: ANM).

Thirdly, knowledge about nutritious food is highly diversified in the district. A few mothers who live in an urban area, who are educated and rich, are perceived to be highly knowledgeable about healthy food but still have poor knowledge on how to prepare it to preserve its nutritional value. One of the policy people drew on personal experience in observing that:

"One of my neighbours who is well off and highly educated never buys green vegetables and fruits from the market because of food adulteration. He always grows them in his own garden. I have also experienced that many mothers from disadvantaged communities do not give priority to child ailments unless the condition of the child gets worse. This type of knowledge is widely practised in Nepal which is creating big problems in the society."

(FGD: Policy People).

All focus group participants, except the spiritual healers, independently voiced similar opinions about mothers' knowledge and perceptions on undernutrition.

\subsection{Policy}

The debate focused on existing health and food policies. The groups of pharmacists and policy people shared their views in the discussion of policies. In contrast, the ANMs, mothers' group and spiritual healers did not discuss policy at all. The latter might be due to a lack of knowledge of health policy including nutrition because of their low socioeconomic status and education compared to the other groups. Additionally, ANMs and mothers' group members may have been concerned that their voices might reach higher authorities and may impact on losing their jobs. For the same reasons, lower level health workers were also observed to be silent or digress from the topic when discussing policy issues concerning higher health authorities.

A major concern was the policy relating to free government health care services. The pharmacists agreed that:

"An officially free health care policy was mainly targeted
at poor and marginalized groups in the society, but
in practice ... disparities remain, as rich people are
getting more benefit than the poor. It is documented in
government records that the service has been used by poor
and disadvantaged groups, but practically it was used by
rich and politically influential people."

(FGD: Pharmacist).

A policy for the provision of free healthcare services at a government facility under the district hospital has been progressively introduced, reducing financial barriers to promote uptake by poor and margin alised groups. However, health inequalities may still occur as the rich may benefit more than the poor from such programmes.

The pharmacists also commented on the weaknesses of child and maternal health policy. The provision was considered to be very different from private and public health institutions and they thought policies must be the same in both institutions. The private health sector does not follow government rules and regulations with regard to public health issues. There was a lack of supervision and monitoring. The poorest women were really deprived of maternity care especially in rural areas. One pharmacist stated that women: 
"Are unfairly discriminated in the society and working institutions of this society. It has been seen that the mothers of malnourished children lack proper healthcare before and after birth because most of the time, mothers are expected to get back to family chores, such as working on the farm or the kitchen just after delivery and it affects the health of the mother and child and their nutrition."

(FGD: Pharmacist).

\subsection{Beliefs about breastfeeding}

Beliefs and attitudes concerning breastfeeding were also associated with wider cultural and traditional beliefs. Most of the female participants showed considerable interest in breastfeeding and felt that breast milk was better than any infant milk formula and an artificial food supplement. A typical comment was:

"I think breastfeeding is highly effective for children. My mother-in-law and mother taught me the importance of breastfeeding and colostrum because there are a lot of rumours about breastfeeding around this society and people don't listen to the facts about breastfeeding and colostrum and they confronted. I also have observed my mother's health which is associated with long-term breastfeeding in the past. She is still beautiful and healthy".

(FGD: ANM).

Most women reported that they squeezed out colostrum due to negative cultural beliefs reinforced by their mothers-inlaw, spiritual healers, and some health workers. One of the mothers in the FGD murmured that:

"In my case, I could not feed colostrum to my children because my mother-in-law forced me to discard colostrum before starting breastfeeding. But I had repeatedly explained to her about the significance of colostrum for the new borne which I had learned from FCHV (Female Community Health Volunteer) despite this she did not agree with me and I was compelled to discard it."

(FGD: Mothers' Group).

\subsection{Food beliefs}

The focus groups highlighted crucial issues about food beliefs. The local mothers' group in the village is trusted by the local women who share health issues. So, they are also respected within the poor and poorly educated communities. Another member of the mothers' group added that:

"Many families ... believe that feeding pregnant women a lot of food will make delivery difficult, so they even reduce the amount of food once they notice the pregnancy.
Thus, I have observed that many pregnant women are being prevented from (eating) healthy food."

(FGD: Mothers' Group).

The health workers, pharmacists, and social workers expressed similar views. Overall participants believed that obese or overweight children healthy children and lowweight babies signify the poor socio economic status of a family. One experienced social worker highlighted:

"In remote parts of Kaski white pumpkin, auberginel eggplants, yoghurt, eggs, green leafy vegetables and some fruits are avoided in pregnancy due to fear of miscarriages. Some ethnic groups believe that these food items can cause harm to the unborn baby and pregnant women are also likely to get common colds and stomach problems which harm the baby. I also heard that in hospital some doctors are also advising women to avoid foods in some sort of conditions. I think these misconceptions generally came out from some of the Hindu scriptures and films as well."

(FGD: Social Worker).

Similarly, one mother from the mothers' group, who are using complementary vitamin packets distributed by the government, cited:

"I have three children, for the first two, I avoided many healthy foods while pregnant because plenty of misconceptions existed about healthy food. During the third time I was pregnant, I did have a nutritious diet which caused a big problem during delivery due to having a larger baby. There are numerous negative beliefs which are associated mainly with children, women and sick people; even I could not remember them (all)."

(FGD: Mothers' Group).

\subsection{Health-seeking behaviour and cultural influences}

With regard to the health-seeking behaviour and the cultural influences, most participants had similar views, except for the spiritual healers. Most groups were able to propose possible reasons for the poor utilization the existing health services (mainly the private one) due to the extreme cost, time, the level of awareness of the household or right decisions and the trust in the healthcare services (for public healthcare). The spiritual-healers and pharmacists highlighted on health-seeking behaviours and the existing cultural influences about healthy diets. More importantly, they added that the cultural environment is completely bounded by the existing religious norms and values. For example, meat items and dairy products are eaten separately. The mothers' group, ANMs, and social workers focused on the health-seeking behaviours from the different angles and 
expressed their experiences more openly. But the group of the spiritual healer expressed that:

"Health institutions are ultimately costly for poor people and worthless mainly in Bhut, Prait and Pichas (spiritual conditions). Thus, people are knocking on our doors because all the mothers care about their children and want to escape from the problems as soon as possible. We are honest, kind and more familiar with the community and we have distinct knowledge on the matter."

(FGD: Spiritual Healer).

The mothers' FGD agreed that most mothers wait for the child to recover by itself before making a short visit to a healer and wait for some days. Only if the child does not recover will they consider attending health institutions. If they do not have enough money, then the child stays at home without treatment. One mother stated that:

"I have heard a lot of voices from many mothers from the community while doing home visits at my clusters when, honestly speaking, the children's mothers expressed that they do not understand the message mainly on medication and diet which is being delivered by health workers."

(FGD: Mothers' Group).

\section{Discussion}

The focus group discussions explored cultural practices and food beliefs, major barriers, causes of undernutrition and personal experiences particularly linked to misconceptions and taboos among parents of preschool-aged children (Barun \& Clarke, 2006; Acharya, 2013; Acharya et al., 2017). The study findings acknowledged poverty, knowledge, existing food beliefs, policy issues, and healthseeking behaviours to be major factors which prevent mothers in providing nutritious food for their children (Onta, 2005).

The discussion reveals that the community or household environments, situation and time mainly influence the provision of a healthy diet to children. The study community is strongly embedded with cultural and religious norms and values that support them to practice the food beliefs within every household routinely (Acharya et al., 2015). The discussions highlight the complexity of nutritious food, socio-cultural beliefs including practices and health-seeking behaviours about the healthy diet. Most of the groups acknowledge social, cultural and environmental elements combined with the routine collection of data and continued support for these populations will be instrumental in maintaining and improving food and health-seeking behaviours in rural and urban mothers and the wider community (Christian et al., 2006; Oent, 2011; Biza-Zepro, 2015).

With regards to food beliefs, the older generation, particularly older women, and Hindu manuscripts and films/dramas were generally blamed for influencing food and health-seeking behaviours (Christian et al., 2006; Acharya, 2013; Acharya et al., 2017). The spiritual healers explained the rationale for sacrificing animals as a pragmatic means to fulfil the patient's nutrient requirements. Spiritual healers were very responsive during the debate on beliefs and taboos, but policy maker sand the pharmacists were relatively less interested in this issue. All participants presented negative and positive beliefs (Sibeko et al., 2005) about food and healthseeking behaviours (Storer, Shakya, 2006; Acharya et al., 2017). Food beliefs, particularly, associated with children, both positive and negative, are strongly embedded in most households in Nepal (Christian et al., 2006; BizaZepro, 2015). It seems that mothers and older women in the households maintain traditional food beliefs. In addition, religious people (e.g. healers/shamans, priests, monks, pastors), herbalists, quacks (fake doctors) and health workers also preserve traditional food beliefs in this community (Christian et al., 2006; Odent, 2011; Acharya et al., 2017). Unfortunate events or incidents that occur within a household or community as a result of consuming certain food items also helps to create negative beliefs about food (Christian et al., 2006; Adhikari, 2010). For example, the majority of mothers do not give pomegranate to children because they believe that it causes constipation. This is an example of perception-based evidence which still existsin the community (Christian et al., 2006; Acharya, 2013).

This study identified 'diversified views' as a major barrier (Acharya et al., 2017) to food recommendations (see Figure 1). Beliefs or mis beliefs about nutritious food are strongly rooted in Nepalese society (Christian et al., 2006; Subba et al., 2007; Odent, 2011). In the past rural communities depended on spiritual healers (Jhankris) and herbal remedies (Jadi-buti), but even today, most people still trust in spiritual healers (Tamang \& Broom, 2010). When people feel unwell they relate this to devils, witchcraft (Boksi) and ghosts (Bhut) and, therefore they go to traditional healer sand use herbs extensively (Subba et al., 2007; Tamang \& Broom, 2010; Acharya et al., 2017). Shamans or healers are still affecting people's beliefs including those associated with foods in this community (Meyer-Rochow, 2009; Tamang \& Broom, 2010; Acharya et al., 2017). They have support and perpetuate this traditional system as it is their main business (Storer, 1977; Biza-Zepro,2015). Thus, these beliefs are still deeply rooted in custom and tradition as they are across other South Asian communities (Christian et al., 2006; Adhikari, 
2010; Oent, 2011: Karkee, Khanal \& Binns, 2014). This study has revealed the concept and complexity of diversified views which present a challenge to ensuring good nutrition for this group and which not discussed in the literature to date (Acharya et al., 2017).

This study revealed the several misconceptions about food, for example, describing colostrum as bighaouti, pip, khoti, bikh, khil, and phohar (yellow or thick substance, pus, poison, and dirt) (Christian et al., 2006; Odent, 2011; Biza-Zepro, 2015). Colostrum is also called a pus within an illiterate community because of its appearance (Sibeko et al., 2005; Christian et al., 2006; Odent, 2011: Azugbene. 2017). Many people still believe that this first milk is an unsafe substance which should be discarded (Christian et al., 2006; Odent, 2011; Acharya et al., 2017). Surprisingly, even the owners of cattle do not give the colostrum to the calves in rural Nepal (Subba et al., 2007; Subedi, 2008; Odent, 2011). The breastfeeding practice is contrary to the World Health Organization's recommendation that breastfeeding should start within the first hour after birth. Fortunately, breastfeeding rates after expelling colostrum were high and expressing still stimulates a mother's milk supply (Odent, 2011).

As per the National Plan of Action of Nepal, the key contributing factors of childhood nutrition were child care practices, women's status, and household food security (Government of India, 1995; Pokharel et al., 2009; 2013). Generally, illiterate people have a strong negative view of certain healthy diets, but thisstudy found there is no difference between educated and non-educated people on this issue (Sah, 2005; Onta, 2005; Christian et al., 2006; Acharya et al., 2017). Educated people are also highly influenced by the social constructs and religious beliefs about contradictions between health and nutritious diets (Christian et al., 2006; Government of India, 1995; Government of Nepal, 2012).

Surprisingly, more than one-fifth of respondents were still not providing several nutritionally rich foods to their children, because they believed them to cause diarrhoea, dysentery, and vomiting or constipation due to a poor digestive system (Mishra \& Retherford, 2000 ; Christian et al., 2006; Odent, 2011; Acharya, 2013; Acharya et al., 2016; Acharya et al., 2017). This study also revealed that urban mothers have more positive beliefs regarding healthy food whereas rural mothers have more negative ones (Adhikari, 2010; Acharya et al., 2017). Nearly one-fourth of respondents have negative perceptions about colostrum, and a similar proportion of the group of mothers still have strong faith in food beliefs which they apply in their daily practice (Odent, 2011).

Another example of food belief, in Nepal, food is considered pure or impure depending upon the food type, source, and handling (Christian et al., 2006; Shakya, 2006; Adhikari, 2010; Acharya, 2013; Acharya et al., 2015). In Nepalese and even in Indian society or culture, the concept of cold and hot food is very significant and still exists, especially in rural communities (Pool, 1987; Subedi, 2002; Shakya, 2006; Odent, 2011). Similarly, cold items are cooling foods such as fruits, green leafy vegetables and other types of vegetables (Pool, 1987; Shakya, 2006; Acharya, 2013; Biza-Zepra, 2015). Likewise, hot items are also prohibited when someone needs to cool off and they are preferred for extra energy and nutrition (Shakya, 2006; Adhikari, 2010; Acharya et al. 2016). Hot and cold beliefs are held by many people in this community (Storer, 1977; Shakya, 2006), together with people from South Asian (Christian et al., 2006; Ellahi, 2014). This concept is thought to originate from the Ancient Hindu medical system of Ayurveda and has been influential in medical practices since ancient times (Pool, 1987; Shakya, 2006; Najar \& Sharma, 2015). The Unani medical system is also thought to have influenced popular thinking which is derived from the Ancient Greek humoral theory, was developed and adopted in areas that were under Muslim rule, for example, Gujarat, after assimilating medical knowledge from India and Persia (Storer, 1977; Pool, 1987). As with Ayurveda, the Unani system includes hot and cold classification, however, the two classifications are not the same (Pool, 1987). Generally, foods with a pungent, acidic or salty taste are considered 'hot, while those with a sweet, astringent or bitter taste, 'cold'. The basic concept of the Ayurveda and Unani medical systems is the maintenance of a dynamic balance in the body (Storer, 1977; Shakya, 2006).

In day-to-day life, little attention tends to be paid to the 'hot' and 'cold' classification of foods with their significance related to vulnerable physiological stages of life such as pregnancy, lactation or illness (Storer, 1977; Christian et al., 2006; Shakya, 2006; Acharya, 2013). Adherence to beliefs also tends to be stronger in the rural community and among the non-literate poor (Sibeko et al., 2005; Onta, 2005; Acharya et al., 2017). Modern-day Asian beliefs regarding hot and cold vary between countries and regions. Correct diet and digestion, together with a power of self-preservation are seen as influential to the maintenance of humoral balance (Mishra \& Retherford, 2000; Subba et al., 2007; UNICEF, 2013). There is thought to be caused by an imbalance in the humour. Many of the spices and seasonings used in South Asian food are believed to have therapeutic qualities, for example, turmeric is considered to have an antiseptic effect and garlic, ginger, cardamom, fenugreek, thyme, asafoetida, and cloves are regarded as good for digestions and combating the bacterial effects often associated with food and the tropics which also relate to diversified views 
(Shakya, 2006; Lobstein \& Davies, 2008). Mothers' group, health workers and ANMs including spiritual healers also highlighted these issues during the focus group discussions and they voiced that, as a therapeutic uses, turmeric powder is commonly consumed by the women after the delivery of the baby in Southern part of Nepal (Lindeman, Keskivaara $\&$ Roschier, 2000; Christian et al., 2006).

As per the simple concept of food, this was interpreted as edible natural resources that are socially acceptable and that aid growth of human body (Lobstein \& Davies, 2008; Odent, 2011; Acharya et al., 2016). This statement reflects the idea that what is considered edible and a form of sustenance is a function of cultural and social meanings. One study in Ghana reports that oily foods are unhealthy which are associated with the risk of diabetes and banned for pregnant women (Odent, 2011; Ellahi, 2014). The results suggest that while social practice and culture informs food beliefs these are aligned with recommended hot and cold food guidelines (Adhikari, 2010; Biza-Zepra, 2015). In Nepal, previous studies have shown the influence of inter-personal relations on food habits. For instance, senior members of the family, mainly, mothers-in-law/mothers/ grandmothers, enforce the existing dietary rules of the ethnic groups and breastfeeding norms on their daughtersin-law/daughters/granddaughters (Christian et al., 2006; Acharya, 2013; Biza-Zepro, 2015). In this study, we found the influence of mothers, grandmothers and wives shaping the food of the participants based on their social practices and religious norms and values. Besides these, the lack of money, limited healthy food practices are also another milestone (Christian et al., 2006). Similarly, the structures of urban areas mean that the people rely on the market for their food supply and most food commodities are purchased. This makes money a key component of the urban food market. Urban poor people usually have limited cash and are more vulnerable to price changes (Odent, 2011; Biza-Zepro, 2015).

Based on cultural beliefs, certain foods are considered inappropriate for women, infants, children, pregnant or lactating women, the sick and the elderly (Christian et al., 2006; Odent, 2011; Biza-Zepro, 2015). The concept of cold and hot diets is relatively common in Nepal, but the standards for categorizing food as cold and hot are not clear because they are not based on scientific principles or logic (Odent, 2011; Biza-Zepro, 2015).

However, the focus groups highlighted policy and strategic considerations which are still insufficient to tackle the issue of undernutrition at a community level (Odent, 2011). The 'beliefs and cultural influences' theme is strongly embedded, with cultural and religious norms and values playing a pivotal role in food recommendations and health- seeking behaviour (Acharya et al., 2016; 2017). Many key findings that came out of the focus group analysis link to the literature and warrant further investigation.

\section{Conclusions}

This study examines lay perspectives of parental food beliefs, drawing on interviews with urban poor households in Kaski district of Nepal. Form a conceptual view point, this study is aligned with existing food and health seeking behaviours and practices about the interplay between individual and social and religious influences on food related behaviours (Lindeman, Keskivaara \& Roschier, 2000; Odent, 2011; Joshi, Barakoti \& Lamsal, 2012; Biza-Zepro, 2015). From the policy view point, this study is aligned with global and national policy emphasis on promotion of healthy lifestyles and healthy eating in societies through nutrition knowledge (Odent, 2011).

There are several misconceptions and practices about the consumption of nutritious foods in the study population, which are generally derived from traditional treatment systems such as Ayurvedic and homeopathic (Shakya, 2006; Biza-Zepro, 2015). These misconceptions are strongly associated with food and health-seeking behaviours including many more other factors (see Figure 1) which prevented mothers from recommending healthy foods to their children (Christian et al., 2006). The results suggest that beliefs food beliefs about nutritious food practices are deep rooted in multi-level issues including household dynamics, community factors and an experience of individual. The issues influencing food choices are also multilevel (Acharya et al., 2017).

\section{Recommendation}

This study reinforces the need to focus on nutritional issues in Nepal and conclude with further investigations particularly focusing on influential elements (Figure 1) including ethnic issues. Nepal urgently needs to develop awareness programmes, using short-, medium-and longterm strategies. Community-level approaches should focus on the use of local resources, promotion of kitchen gardening and improve on infant child feeding practices. Likewise, at the policy Nepal should focus on the implementation and evaluation of the programme within the government health network and, donors' agencies should appropriate interventions and research.

The study suggests an urgent requirement for addressing the existing food beliefs issues by implementing extensive mass awareness programme focusing on cultural and religious issues which are strongly associated with healthy diets. Thus, it is recommended to implement "the 3P awareness strategy" for this purpose that focuses on the Policies, Professionals and People (in the community). 


\section{Acknowledgement}

We would like to convey our sincere gratitude to Sight and Life, Switzerland, GSGP/Open Society Foundation-Europe, and Bournemouth University, England for their generous support towards this study. The authors would like to thank Child Welfare Scheme Nepal, Pokhara Metropolitan City, Western Regional Health Directorate, WRH Training Centre, District Public Health Office Pokhara, GONESA Nepal, La' Grande International College Pokhara for their support in data collection. We also thanks to all participants who contributed their invaluable information.

\section{Authorships}

Dr Acharya (JA) conceptualised and designed the study. JA also had collected and analysed data from the field and Prof. Edwin van Teijlingen (EvT) had revised the data entry and analysis processes. EvTrevised ang given crucial input for the result section of the manuscript. Professors Edwin van Teijlingen, Murphy and Ellahicritically revised the content of this manuscript and the presentation of the findings.

\section{Conflicts of Interest}

Authors of this manuscript have no any conflicts of interest with publication of the manuscript or an institution or products used in the manuscript.

\section{References}

Acharya, O., Zotor, F., Chaudhary, P., Deepak, K., Amuna, P., \& Ellahi, B. (2016). Maternal Nutritional Status, Food Intake and Pregnancy Weight Gain in Nepal. Journal of Health Management, 18(1), 1-12. https:// doi.org/10.1177/0972063415625537

Acharya, J., Teijlingen, E., Murphy, J., \& Hind, M. (2015). A Comparative Study on Nutritional Problems in Preschool Aged Children of Nepal. European Journal of Nutrition \& Food Safety, 5(5), 389-389. https://doi. org/10.9734/ejnfs/2015/20873

Acharya, J., Van Teijlingen, E., Hind, M., \& Murphy, J. (2017). Food belief practices amongst rural and urban mothers in Nepal: A qualitative overview. In: BNAC 15th Nepal Study Days, 12-13 April 2017, EBC Bournemouth University. Retrieved on September 27, 2018 from http://eprints.bournemouth.ac.uk/28834/

Acharya, B. (2013). Food Belief And Practices During Postoperative Period Among Post-Operative Patient. https://fdocuments.in/document/food-belief-andpractices-during-postoperative-period-among-postoperative-patient-by-binita-acharya-2013-bn.html
Adhikari, D. (2013, August 09). Malnutrition is Alarmingly High in Nepal. Spotlight. Retrieved from https://www. spotlightnepal.com/News/Article/nepal-malnutritionhigh

Adhikari, R. (2010). Food Utilization Practices, Beliefs and Taboos in Nepal (No. 10-01-367). https://pdf.usaid. gov/pdf_docs/pnaeb772.pdf

Azugbene, E. (2017). Maternal Health Literacy and Maternal and Child Health Outcomes: A Review of the Literature. Annals of Global Health, 83(1), 94. https://doi.org/10.1016/j.aogh.2017.03.208

Bista, K.P., Karki, Y., \& Thapa, K. (2010). Myths and Misconceptions about Abortion Among Marginalized Underserved Community. Journal of Nepal Medical Association, 48(176), 276-280. https://doi. org/10.31729/jnma.353

BizaZepro, N. (2015). Food Taboos and Misconceptions Among Pregnant Women of Shashemene District, Ethiopia, 2012. Science Journal of Public Health, 3(3), 410-416. https://doi.org/10.11648/j. sjph.20150303.27

Bowling, A. (2014). Research methods in health: investigating health and health services (4th edition). Open University Press.

Braun, V., \& Clarke, V. (2006). Using thematic analysis in psychology. Qualitative Research in Psychology, 3(2), 77101. https://doi.org/10.1191/1478088706qp063oa

Christian, P., Srihari, S.B., Thorne-Lyman, A., Khatry, S., LeClerq, S., \& Shrestha, S.R. (2006). Eating Downin Pregnancy: Exploring Food-Related Beliefs and Practices of Pregnancy in Rural Nepal. Ecology of Food and Nutrition, 45(4), 253-278. https://doi. org/10.1080/03670240600846336

Devkota, M.D., Uprety, A., Subedi, N., \& Poudel, R. (2012). Identification of gaps and priority interventions for maternal nutrition in Nepal: A review child health division. Kathmandu, Ministry of Health and Population and World Health Organization. https://dohs.gov.np/wp-content/uploads/chd/ Nutrition/Maternal_Nutrition_Review_Report_23_ March_2012.pdf.

Ellahi, B. (2014). Dietary intake patterns of south Asian men attending mosques in Burnley UK. Webmadecentral Biology, 5(10): WMC004721. https:// doi.org/10.9754/journal.wmc.2014.004721

Fieldhouse, P. (1995). Customs and Culture (2nd edition). London: Chapman \& Hall.

HKI (2014). Helping Families Grow Better Food: Improving Nutrition. http://www.hki.org/our-work/improvingnutrition/helping-families-grow-better-food 
Horton, R. (2008). Maternal and child under nutrition: an urgent opportunity. The Lancet, 371(9608), 179. https://doi.org/10.1016/s0140-6736(07)61869-8

Hunter, M., \& Shaw, C. (1989). Nutrition and the elderly. Nursing Standard, 4(2), 38-40. https://doi. org/10.7748/ns.4.2.38.s38

Joshi, S.K., Barakoti, B., \& Lamsal, S. (2012). Colostrum Feeding: Knowledge, Attitude and Practice in Pregnant Women in a Teaching Hospital in Nepal. Webmedcentral Medical Education, 3(8): WMC003601. https://doi. org/10.9754/journal.wmc.2012.003601

Karkee, R., Lee, A., Khanal, V., \& Binns, C. (2014). Infant feeding information, attitudes, and practices: a longitudinal survey in central Nepal. International Breastfeeding Journal, 9(1), 14. https://doi. org/10.1186/1746-4358-9-14

Karkee, R., Lee, A.H., \& Binns, C.W. (2013). Why Women do not Utilize Maternity Services in Nepal: A Literature review. WHO South-East Asian Journal of Public Health, 2(3-4), 135-141.

Lindeman, M., Keskivaara, P., \& Roschier, M. (2000). Assessment of Magical Beliefs about Food and Health. Journal of Health Psychology, 5(2), 195-209. https:// doi.org/10.1177/135910530000500210

Lobstein, T., \& Davies, S. (2008). Defining and labelling 'healthy' and 'unhealthy' food. Public Health Nutrition, 12(3), 331-340. https://doi.org/10.1017/ S1368980008002541

Meyer-Rochow, V.B. (2009). Food taboos: their origins and purposes. Journal of Ethnobiology and Ethnomedicine, 5(1), 18. https://doi.org/10.1186/1746-4269-5-18

MoHP, New Era, ICF. (2017). Nepal Demographic And Health Survey 2016: Key Indicators. Kathmandu, Nepal: Ministry of Health.

Mishra, V.K., \& Retherford, R.D. (2000). Women's education can improve child nutrition in India. Mumbai, India: International Institute for Population Sciences and Honolulu: East-West Center. https://scholarspace. manoa.hawaii.edu/handle/10125/3468

Government of India (1995). National Plan for Action on Nutrition. Food and Nutrition Board and Ministry of Women \& Child Development. http://www. nipccd-earchive.wcd.nic.in/sites/default/files/PDF/ National\%20Plan\%20 of\%20Action \%20on\%20 nutrition\%20-1995.pdf

Najar, N., \& Sharma, B. (2015, July 28). 11 arrested following 'human sacrifice' in Nepal. The Hindu. https://www.thehindu.com/news/international/11arrested-following-human-sacrifice-in-nepal/ article7471410.ece.
Government of Nepal (2012). National Population and Housing Census 2011. Government of Nepal: National Planning Commission. https://unstats.un.org/unsD/ demographic/sources/census/wphc/Nepal/NepalCensus-2011-Vol1.pdf

Odent, P.L.G. (2011). Early infant feeding and neonatal survival in Nepal: breastfeeding, colostrum, and discarding of the first milk. Doctoral Thesis, UCL (University College London). https://discovery.ucl. ac.uk/id/eprint/1310430/

Onta, S. (2003). Knowledge, practice, and coverage final survey in Kanchanpur district Nepal. https://pdf.usaid. gov/pdf_docs/Pnadc698.pdf

Pokharel, R.K., Houston, R., Harvey, P., Bishwakarma, R., Adhikari, J., Pant, K.D., \& Gartoulla, R. (2009). Nepal nutrition assessment and gap analysis. Kathmandu: MOHP. https://pdf.usaid.gov/pdf_docs/pnaea792.pdf

Pool, R. (1987). Hot and cold as an explanatory model: The example of Bharuch district in Gujarat, India. Social Science \& Medicine, 25(4), 389-399. https://doi. org/10.1016/0277-9536(87)90277-2

Pokharel, R.K., Houston, R., Harvey, P., Bishwakarma, R., Adhikari, J., Pant, K.D., \& Gartoulla, R. (2013). Nepal Nutrition Assessment And Gap Analysis Final Report Nutrition Assessment Team. Kathmandu, Nepal: Child Health Division, MOHP.

Sah, N. (2005). Determinants of child malnutrition in Nepal: A case analysis from Dhanusha, central Terai of Nepal. Journal of Nepal Health Research Council, 2(2), 50-55.

Shakya, M. (2006). Traditional Food and Health Beliefs. Education and Development, 2006(Special Issue), 5868.

Sibeko, L., Dhansay, M.A., Charlton, K.E., Johns, T., \& GrayDonald, K. (2005). Beliefs, Attitudes, and Practices of Breastfeeding Mothers From a Periurban Community in South Africa. Journal of Human Lactation, 21(1), 31-38. https://doi.org/10.1177/0890334404272388

Sreeramareddy, C.T., Shankar, R.P., Sreekumaran, B.V., Subba, S.H., Joshi, H.S., \& Ramachandran, U. (2006). Care seeking behaviour for childhood illnessa questionnaire survey in western Nepal. BMC International Health \& Human Rights, 6(1), 7. https://doi.org/10.1186/1472-698x-6-7

Storer, J. (1977). 'Hot' and 'Cold' food beliefs in an Indian community and their significance. Journal of Human Nutrition, 31(1), 33-40.

Subedi, M. (2008). Healer choice in medically pluralistic cultural settings: An overview of Nepali medical pluralism. Occasional Papers in Sociology and 
Anthropology, 8, 128-158. https://doi.org/10.3126/ opsa.v8i0.1125

Subedi, M. (2002). Explanatory model of Food, Health and Illness Ideology in Newar Town of Kirtipur. https:// www.academia.edu/4037779/Explanatory_model_ of_Food_Health_and_Illness_Ideology_in_Newar_ Town_of_Kirtipur.

Subba, S.H., Chandrashekhar, T.S., Binu, V.S., Joshi, H.S., Rana, M., \& Dixit, S.B. (2007). Infant feeding practices of mothers in an urban area in Nepal. Kathmandu University Medical Journal, 5(1), 42-47.

Tamang, A., \& Broom, A. (2010). The practice and meanings of spiritual healing in Nepal. South Asian History and Culture, 1(2), 328-340.
Toyama, N. (2000). Young children's awareness of socially mediated rejection of food. Cognitive Development, 15(4), 523-541. https://doi.org/10.1016/s0885 2014(01)00041-7

UNICEF (2013). Capacity Building to Strengthen Local Government and Community Participation in Multi-Sectoral Nutrition Programmes in Nepal. https://wphna.org/wp-content/uploads/2013/10/ multisectoral-nutrition-programs-NEPAL.pdf

Van Teijlingen, E., \& Hundley, V. (2005). Pilot studies in family planning and reproductive health care. Journal of Family Planning and Reproductive Health Care, 31(3), 219-221.

\section{司 \\ CHITKARA}

\section{Journal of Multidisciplinary Research in Healthcare}

Chitkara University, Saraswati Kendra, SCO 160-161, Sector 9-C, Chandigarh, 160009, India

\section{Volume 7, Issue 1}

October 2020

ISSN 2393-8536

Copyright: [@ $2020 \mathrm{Jib}$ Acharya et al.] This is an Open Access article published in Journal of Multidisciplinary Research in Healthcare (J. Multidiscip. Res. Healthcare) by Chitkara University Publications. It is published with a Creative Commons Attribution- CC-BY 4.0 International License. This license permits unrestricted use, distribution, and reproduction in any medium, provided the original author and source are credited. 